\title{
Tetrameristaceae (Angiospermae: Ericales): primeiro registro da família para o Brasil
}

\author{
PEDRO LAGE VIANA ${ }^{1,4}$, FERNANDA ANTUNES CARVALHO $^{2}$ e ISABEL REIS SILVA ${ }^{3}$
}

(recebido: 20 de maio de 2009; aceito: 29 de abril de 2010)

\begin{abstract}
Tetrameristaceae (Angiospermae: Ericales): first record of the family in Brazil). Tetrameristaceae is a small Angiosperm family included in Ericales clade with three known genera, Tetramerista, Pentamerista and Pelliciera, never recorded before in Brazil. Biological inventories carried out at the Madeira - Purus rivers interfluvial region from April to June 2007, recorded the occurrence of Pentamerista neotropica Maguire in Brazil, which is the first citation of Tetrameristaceae family in this country. This record is approximately $1.000 \mathrm{~km}$ distant from the localities where this species has been previously recorded. This kind of discovery demonstrates the necessity of more fieldwork towards a better knowledge of plant diversity in the Brazilian Amazon forest.
\end{abstract}

Key words - Amazon savannas, campina, Madeira-Purus interfluvial region, Pentamerista neotropica

RESUMO - (Tetrameristaceae (Angiospermae: Ericales): primeiro registro da família para o Brasil). Tetrameristaceae é uma pequena família da ordem Ericales com três gêneros conhecidos, Tetramerista, Pentamerista e Pelliciera, e nenhuma espécie até então registrada para o Brasil. Expedições de inventário biológico na região do interflúvio Madeira-Purus, realizadas nos períodos de abril a maio de 2007 e julho de 2007, registraram a ocorrência de Pentamerista neotropica Maguire no Brasil, sendo primeira citação da família Tetrameristaceae para o País. Este registro dista aproximadamente $1000 \mathrm{~km}$ das localidades para qual era anteriormente conhecida. Descobertas como estas demonstram a necessidade de muito esforço de campo para um conhecimento satisfatório da diversidade florística na Amazônia brasileira.

Palavras-chave - campina, interflúvio Madeira-Purus, Pentamerista neotropica, savanas amazônicas

\section{Introdução}

Tetrameristaceae é uma pequena família da ordem Ericales (APG II 2003, APG III 2009), ocorrente em regiões tropicais da Ásia e Américas. O número de gêneros varia entre diferentes autores. Kubitzki (2004) e Janssens et al. (2005) reconhecem apenas Tetramerista, com três espécies no sudeste da Ásia (sul da Malásia, Sumatra e Borneo), e Pentamerista, gênero monotípico do norte da América do Sul. Outros autores (Bremer et al. 2002, Lens et al. 2007), incluem em Tetrameristaceae Pelliciera rhizophorae Planch. \& Triana, espécie dos mangues da América Central e norte da América do Sul considerada por Kubitzki (2004) como pertencendo à

\footnotetext{
1. Universidade Federal de Minas Gerais, Departamento de Botânica, Instituto de Ciências Biológicas, 30123-970 Belo Horizonte, MG, Brasil.

2. Instituto Nacional de Pesquisas da Amazônia, 69060-001 Manaus, AM, Brasil.

3. Universidade Federal do Amazonas, Instituto de Ciências e Tecnologia, Av. Nossa Senhora do Rosário, 3863, 69000-100 Itacoatiara, AM, Brasil.

4. Autor para correspondência: vianapl@yahoo.com.br
}

família monotípica Pellicieraceae. No sistema APG (APG II 2003, APG III 2009), a inclusão de Pellicieraceae é aceita como uma opção dentro de Tetrameristaceae. Para descrições da família Tetrameristaceae, ver Kubitzki (2004) ou Miller \& Berry (2005).

A única espécie de Tetrameristaceae sensu Kubitzki (2004) ocorrente na América do Sul, Pentamerista neotropica Maguire, é conhecida da Amazônia venezuelana (Estado do Amazonas), em savanas e bordas de florestas em solos arenosos, nas bacias dos rios Orinoco (Caño Caname, Cerro Yapacana, Guarinuma) e Negro (Río Pasimoni) em altitudes entre 100 a 200 m (Miller \& Berry 2005).

A Amazônia Brasileira representa cerca de $40 \%$ de todas as florestas tropicais do planeta (Laurance et al. 2001), ocupando 59\% do território nacional com uma área de aproximadamente $3.800 .000 \mathrm{~km}^{2}$. Entretanto, o difícil acesso mantém muitas regiões isoladas e, portanto, desconhecidas para a ciência. Estudos de modelagem mostram a existência de grandes lacunas de conhecimento botânico na Amazônia brasileira (Nelson et al. 1990, Hopkins 2007). Segundo estes autores os registros em herbários se concentram a 
áreas restritas, o que revela uma falsa noção da real diversidade florística e distribuição geográfica de espécies amazônicas.

\section{Material e métodos}

Expedições de inventário biológico na região do interflúvio Madeira-Purus foram realizadas nos períodos de abril a maio de 2007 e julho de 2007, como parte do projeto "Biodiversidade do Interflúvio Madeira-Purus", coordenado pelo Instituto Nacional de Pesquisas da Amazônia.

Coletas de material botânico, concentradas em áreas de savana mal drenadas, foram realizadas objetivando uma listagem florística preliminar neste ambientes. Tais ambientes apresentam predominância de espécies herbáceas (Poaceae, Cyperaceae, Xyridaceae, Rapateaceae, Eriocaulaceae) e arbustivas (Clusiaceae, Humiriaceae, Rubiacecae, Arecaceae, Vochysiaceae).

Todo o material em estado fértil encontrado foi coletado e herborizado de acordo com técnicas usuais (Fidalgo \& Bononi 1986). As amostras encontram-se depositadas no Herbário INPA, em Manaus.

\section{Resultados e discussão}

Dentre as diversas espécies encontradas nas áreas inventariadas, destaca-se o registro de Pentamerista neotropica, a primeira citação da família Tetrameristaceae para o Brasil. A espécie foi encontrada apenas em uma mancha vegetação aberta, ou campina, onde é relativamente rara. Esta campina ( $4^{\circ} 54^{\prime} 13^{\prime}$ 'S, $\left.61^{\circ} 06^{\prime} 15^{\prime} \mathrm{W}\right)$, cujo acesso é exclusivamente aéreo, situa-se a aproximadamente a $230 \mathrm{~km}$ a sudoeste de Manaus, no Município de Borba e dista aproximadamente $1000 \mathrm{~km}$ das localidades para qual esta espécie foi registrada na Venezuela (Miller \& Berry 2005).

Pentamerista neotropica Maguire, Mem. New York Bot. Gard. 23: 187-192. 1972.

Figuras 1-3

Árvore 3-6 m. Folhas alternas espiraladas, concentradas no ápice dos ramos, simples, inteiras, 7,2-11,4 × 2-4,1 cm, sésseis a subsésseis, levemente assimétricas, glabras, com superfície papilosa na face abaxial; base decurrente, ápice arredondado, levemente emarginado; pecíolo, quando presente, até $3 \mathrm{~mm}$ compr.; nervura central saliente em ambas as faces, nervuras secundárias e terciárias pouco evidentes na face adaxial abaxial. Inflorescência em racemos axilares; pedúnculo 5-8,7 cm comp.; pedicelo 1,4-2 mm comp., subentendido por uma ou duas bractéolas caducas, de 2-2,7 mm comp. Flores monóicas, pentâmeras, actinomorfas, 9,5-10,5 $\mathrm{mm}$ diam.; sépalas 5, livres, oblongas, 4,4-5,8 × 2-2,6 mm, verde-amareladas, com pequenas glândulas na superfície adaxial; pétalas 5 , livres, oblongas, 4,7-5,8 × 1,3-2 mm, verde amareladas; estames 5, 1,9-2,6 mm, alternos às pétalas, filetes conados na base, com anteras oblongo-sagitadas, reflexas após a deiscência; ovário súpero, 5,1-5,6 × $2 \mathrm{~mm}$, com 5 carpelos e 5 lóculos, glabro; estilete terminal, cilíndrico, com estigma curtamente 5-lobado; óvulos um por lóculo. Fruto bacáceo, esferoidal a elipsóide, 1,5-2 × 0,8-1,5 cm, esverdeado quando imaturo, atropupúreo quando maduro.

Material examinado: BRASIL. AmAzonas: Borba, 454'13" S, 61 ${ }^{\circ} 06^{\prime} 15^{\prime \prime} \mathrm{W}, 13-\mathrm{VII}-2007$, P.L. Viana et al. 3108 (INPA); Borba, campina aberta, 19-VII-2007, I.R. Silva 137 (INPA).

No local de coleta, $P$. neotropica é uma pequena árvore de aproximadamente 3 a $6 \mathrm{~m}$ de altura, com copa arredondada e troncos tortuosos. Suas flores são dispostas em discretos racemos axilares nas extremidades dos ramos e possuem coloração verde-amarelada. Para descrição e ilustrações adicionais, ver Miller \& Berry (2005).

Considerando as extensas lacunas de conhecimento botânico na Amazônia brasileira (Hopkins 2007), a ocorrência no Brasil de espécies conhecidas de países vizinhos não é um fato extraordinário. A composição da flora brasileira sofre crescente incremento de espécies, pela descrição de novos táxons ou registros de espécies ainda não citadas para o país.

$\mathrm{O}$ registro de $P$. neotropica no Brasil, entretanto, releva-se pelo fato de ser uma espécie previamente conhecida por poucas coletas (Miller \& Berry 2005), de uma área geográfica relativamente restrita, em savanas nas regiões limítrofes entre Venezuela e Colômbia. A ocorrência dessa espécie numa região significativamente distante de onde era conhecida, em pequenas manchas savânicas no Interflúvio Madeira-Purus, revela dados importantes para o entendimento do histórico das formações savânicas amazônicas e também para a história evolutiva do grupo.

Em recente levantamento das famílias e gêneros de angiospermas ocorrentes no Brasil, organizadas no sistema APG II (2003), Souza \& Lorenzi (2005) citaram 217 famílias nativas. Neste trabalho, os autores não citam a ocorrência da família Tetrameristaceae. Com o registro de P. neotropica no Estado do Amazonas, podem ser formalmente reconhecidas 218 famílias de plantas floríferas nativas no Brasil de acordo com o sistema da APG II (2003). 

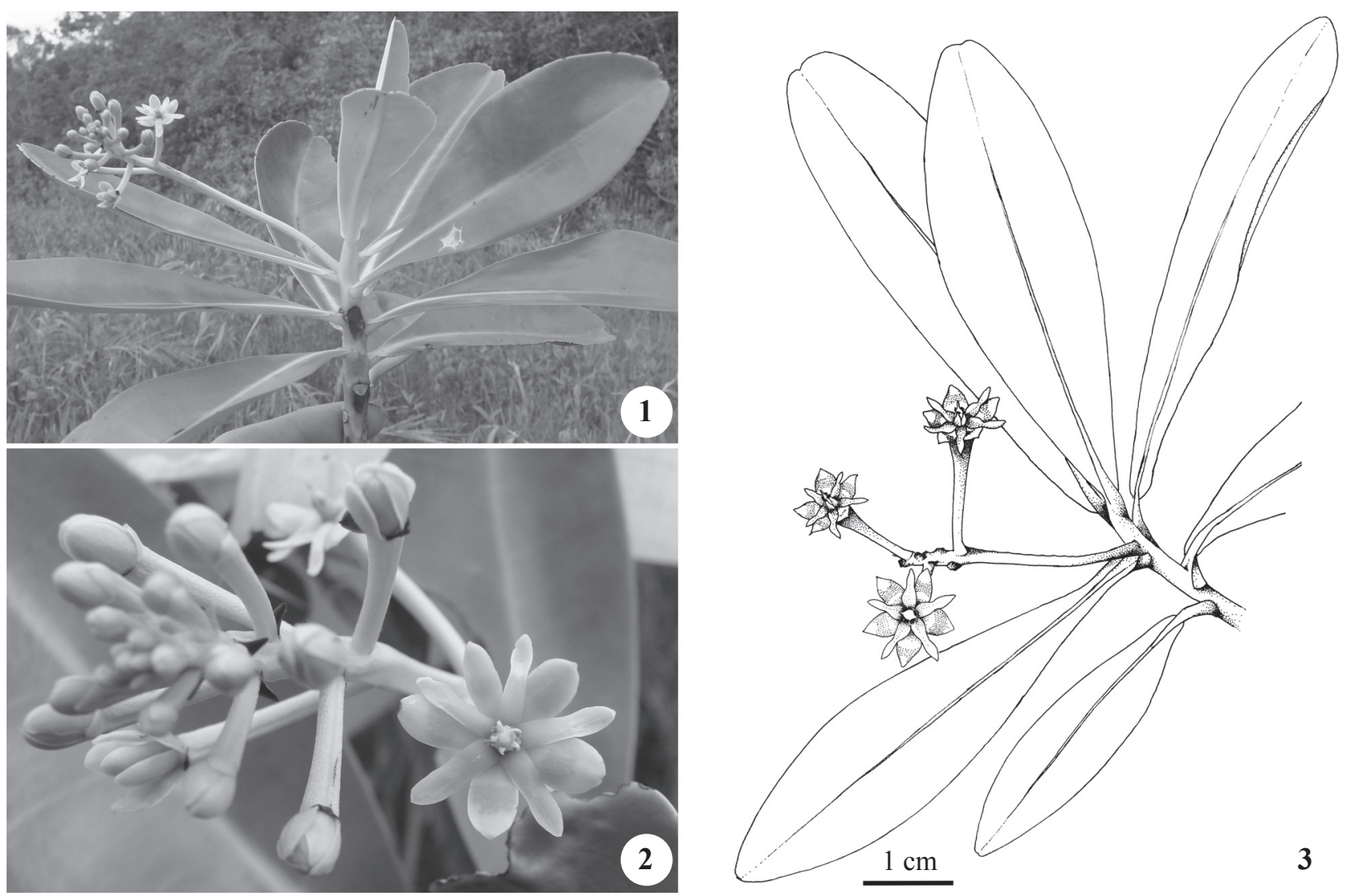

Figuras 1-3. Pentamerista neotropica. 1. Ramo florífero. 2. Detalhe da inflorescência (Viana et al. 3108). 3. Ilustração do ramo florífero (Silva et al. 137).

Figure 1-3. Pentamerista neotropica. 1. Flowering branch. 2. Detail of inflorescence (Viana et al. 3108). 3. Flowering branch illustration (Silva et al. 137).

Agradecimentos - Este trabalho é um produto do projeto "Biodiversidade do Interflúvio Madeira-Purus", uma atividade da rede Geoma do Ministério da Ciência e Tecnologia. Os autores agradecem aos pesquisadores Dr. Marcos Sobral, pela ajuda na identificação do material, Dr. Mario CohnHaft, Dr. Michael Hopkins e Dr. Eduardo L. Borba, pelo apoio, e especialmente ao colega de campo Raimundo da Luz, o "Grafite" (in memoriam), quem primeiramente avistou os indivíduos de Pentamerista neotropica citados nesse trabalho.

\section{Referências bibliográficas}

APG II. 2003. An update of the Angiosperm Phylogeny Group classification for the orders and families of flowering plants: APG II. Botanical Journal of the Linnean Society 141:399-436.

APG III. 2009. An update of the Angiosperm Phylogeny Group classification for the orders and families of flowering plants: APG III. Botanical Journal of the Linnean Society 161:105-121.
BREMER, B., BREMER, K., HEIDARI, N., ERIXON, P., OLMSTEAD, R.G., ANDERBERG, A.A., KALLERSJO, M. \& BARKHORDARIAN, E. 2002. Phylogenetics of asterids based on 3 coding and 3 noncoding chloroplast DNA markers and the utility of noncoding DNA at higher taxonomic levels. Molecular Phylogenetics and Evolution 24:274-301.

FIDALGO, O. \& BONONI, V.L.R. 1984. Técnicas de Coleta, preservação e herborização de material botânico. Instituto de Botânica, São Paulo.

HOPKINS, M.J.G. 2007. Modelling the known and unknown plant biodiversity of the Amazon Basin. Journal of Biogeography 34:1400-1411

JANSSENS, S., LENS, F., DRESSLER, S., GEUTEN, K., SMETS, E. \& VINCKIER, S. 2005. Palynological variation in Balsaminoid Ericales. II. Balsaminaceae, Tetrameristaceae, Pellicieraceae and general conclusions. Annals of Botany 96:1061-1073.

KUBITZKI, K. 2004. The families and genera of vascular plants, Flowering plants. Dicotyledons: Celastrales, Oxalidales, Rosales, Cornales, Ericales. Springer-Verlag, New York, v.6. 
LAURANCE, W.F., COCHRANE, M.A., BERGEN, S., FEARNSIDE, P.M., DELAMÔNICA, P., BARBER, C., D'ANGELO, S. \& FERNANDES, T. 2001. The future of the Brazilian Amazon. Science 291:438-439

LENS, F., SCHÖNENBERGER, J., BAAS, P., JANSEN, S. \& SMETS, E. 2007. The role of wood anatomy in phylogeny reconstruction of Ericales. Cladistics 23:229254.

MILLER, J.S. \& BERRY, P.E. 2005. Tetrameristaceae. In Flora of the Venezualan Guayana. v.9. Rutaceae - Zygophyllaceae (J.A. Steyermark, P.E. Berry, K. Yatskievych \& B.K. Holst, eds.). Missouri Botanical Garden Press, St. Louis, p.307-308.
NELSON, B.W., FERREIRA, C.A., SILVA, M.F. \& KAWASAKI, M.L. 1990. Refugia, endemism centers and collecting density in Brazilian Amazonia. Nature 354:714-716.

SOUZA, V.C. \& LORENZI, H. 2005. Botânica sistemática: guia ilustrado para identificação das famílias de Angiospermas da flora brasileira, baseado em APG II. Instituto Plantarum, Nova Odessa. 